\title{
Three-dimensional lithiophilic Cu@Sn nanocones for dendrite-free lithium metal anodes
}

\author{
Rui Wang ${ }^{\dagger}$, Faxing Shi ${ }^{\dagger}$, Xin He, Jinqiang Shi, Tao Ma, Song Jin and Zhanliang Tao*
}

\begin{abstract}
The uneven deposition of lithium (Li) on current collectors causes serious dendrite growth and volume expansion. Commercial foamed copper $(\mathrm{Cu})$ current collectors are unsuitable for $\mathrm{Li}$ anodes because of their large volume and mass and lithiophobic nature. Herein, a three-dimensional (3D) copper@tin (Cu@Sn) nanocone current collector with small volume, light weight, and lithiophilic nature was prepared by a simple electrodeposition method. The synergy of the nanoconical structure and lithiophilic Sn promotes the even deposition of $\mathrm{Li}$ and effectively inhibits the formation of Li dendrites. The resultant half batteries exhibit high Coulombic efficiency of $97.6 \%$ after 100 cycles at $1 \mathrm{~mA} \mathrm{~cm}^{-2}$, and the symmetrical Li battery demonstrates a prolonged lifespan of over $600 \mathrm{~h}$ at $1 \mathrm{~mA} \mathrm{~cm}$. The full battery based on organic liquid electrolyte with $\mathrm{LiFePO}_{4}$ also exhibits a long lifespan of 550 cycles with high capacity retention of $95.1 \%$ at $1 \mathrm{C}$. Moreover, 3D Cu@Sn nanocone-based solid-state batteries exhibit excellent electrochemical performance and show no decay after 500 cycles at $1 \mathrm{C}$. Our work provides a strategy for fabricating $3 \mathrm{D}$ current collectors for high-energy-density $\mathrm{Li}$ metal batteries.
\end{abstract}

Keywords: lithium metal anode, current collector, 3D structure, lithiophilic, Cu@Sn nanocones

\section{INTRODUCTION}

Lithium (Li) metal is deemed the "holy grail" anode owing to its high theoretical specific capacity (3860 $\left.\mathrm{mA} \mathrm{h} \mathrm{g}^{-1}\right)$ and low negative potential $(-3.04 \mathrm{~V} v s$. standard hydrogen electrode) [1-3]. Li metal anode-based batteries, such as $\mathrm{Li}-\mathrm{S}$ and $\mathrm{Li}-\mathrm{O}_{2} / \mathrm{CO}_{2}$ batteries, can be used as high-energy-density battery systems to meet the requirements of electric vehicles [4-8]. However, volume change during Li plating/stripping processes and the existence of $\mathrm{Li}$ dendrites in $\mathrm{Li}$ metal anodes impede their applications $[9,10]$. Thus, the use of Li metal anodes in- duces low Coulombic efficiency (CE) and may result in a short circuit of the battery and even cause fire or explosion $[11,12]$.

Considerable effort has been undertaken to address these issues of Li metal anodes, such as the use of electrolyte additives [13-15], artificial solid electrolyte interface (SEI) films [16-18], solid-state electrolyte [19-21], and three-dimensional (3D) current collectors [22-24], all of which have yielded significant results. Among them, the 3D current collector can effectively suppress Li dendrites and its $3 \mathrm{D}$ structure can also serve as a host for $\mathrm{Li}$ deposition and mitigate volume expansion during cycling [25-27]. However, commercially available metal foam skeletons, such as copper $(\mathrm{Cu})$ and nickel $(\mathrm{Ni})$ foams, are not particularly suitable for $\mathrm{Li}$ metal batteries (LMBs) owing to their large volume and mass, which can decrease the energy density of the battery [28,29]. Furthermore, the weak interaction among $\mathrm{Cu}, \mathrm{Ni}$, and $\mathrm{Li}$ causes the uneven deposition of $\mathrm{Li}$ and generates $\mathrm{Li}$ dendrites $[30,31]$. Therefore, the modification of a lithiophilic material is necessary for current collectors using approaches such as atomic layer deposition (ALD) of $\mathrm{ZnO}$ and $\mathrm{Al}_{2} \mathrm{O}_{3}$, which improve the affinity between current collectors and Li $[32,33]$ but typically require specialized equipment and high cost. Thus, the direct modification of planar $\mathrm{Cu}$ foil using an economical and simple method for preparing $3 \mathrm{D}$ lithiophilic $\mathrm{Cu}$ current collector is essential for practical use.

Herein, a 3D copper@tin (Cu@Sn) nanocone current collector with small volume, light weight, and lithiophilic characteristics was prepared using a simple electrodeposition approach to grow $\mathrm{Sn}$-modified $\mathrm{Cu}$ nanocone array on a planar Cu foil. The 3D structure of the $\mathrm{Cu@Sn}$ nanocones can facilitate uniform electric field and the dispersion of current density. Moreover, Sn can react with $\mathrm{Li}$ to form $\mathrm{Li}-\mathrm{Sn}$ alloy, and act as the initial Li nucleation

Key Laboratory of Advanced Energy Materials Chemistry (Ministry of Education), College of Chemistry, Nankai University, Tianjin 300071, China

† These authors contributed equally to this work.

* Corresponding author (email: taozhl@nankai.edu.cn) 
sites to enable even deposition of Li. The synergy of 3D nanoconical structure and lithiophilic Sn promotes the uniform deposition of $\mathrm{Li}$ and effectively inhibits $\mathrm{Li}$ dendrites. Thus, CEs of $97.6 \%$ and $96.6 \%$ were maintained after 100 and 250 cycles at current densities of 1 and $0.5 \mathrm{~mA} \mathrm{~cm}^{-2}$, respectively. The assembled $\mathrm{Li} \mid \mathrm{Li}$ symmetrical battery based on Cu@Sn nanocones exhibited a prolonged lifespan $\left(600 \mathrm{~h}\right.$ at $\left.1 \mathrm{~mA} \mathrm{~cm}{ }^{-2}\right)$. The liquid full battery $\mathrm{Li} / \mathrm{Cu} @ \mathrm{Sn} \mid \mathrm{LiFePO}_{4}$ (LFP) maintained capacity retention of $95.1 \%$ after 550 cycles at 1 C. Furthermore, a polyvinylidene fluoride-hexafluoropropylene-based solid electrolyte (PVDF-HFP-5 $\mathrm{wt} \% \mathrm{SiO}_{2}$ ) was prepared and a solid-state full battery Li/Cu@Sn|PVDF-HFP-5 wt\% $\mathrm{SiO}_{2} \mid \mathrm{LFP}$ was assembled to determine the electrochemical performance of the $\mathrm{Cu@Sn} \mathrm{nanocones} \mathrm{in} \mathrm{the} \mathrm{solid-state}$ battery. Results indicated excellent cyclic stability of the battery in which the discharge capacity showed no decay after 500 cycles at $1 \mathrm{C}$. The use of the Cu@Sn nanocone current collector and solid-state electrolyte is expected to further improve and ensure safe performance of batteries more suitable for commercial applications.

\section{EXPERIMENTAL SECTION}

\section{Chemicals and materials}

All reagents used in this study were of analytical grade and used without further treatment. Copper sulfate $\left(\mathrm{CuSO}_{4} \cdot 5 \mathrm{H}_{2} \mathrm{O}, 99 \%\right)$ and nickel sulfate $\left(\mathrm{NiSO}_{4} \cdot 6 \mathrm{H}_{2} \mathrm{O}\right.$, 99.9\%) were purchased from Macklin (Shanghai, China). Sodium hypophosphite $\left(\mathrm{NaH}_{2} \mathrm{PO}_{2}, 99 \%\right)$ was acquired from Innochem (Beijing, China). Sodium citrate $\left(\mathrm{Na}_{3} \mathrm{C}_{6} \mathrm{H}_{5} \mathrm{O}_{7} \cdot 2 \mathrm{H}_{2} \mathrm{O}\right.$, 99\%) was obtained from Heowns (Tianjin, China). Polyethylene glycol (PEG, molecular weight $=2000)$, boric acid $\left(\mathrm{H}_{3} \mathrm{BO}_{3}, 99.99 \%\right)$, sodium hydroxide $(\mathrm{NaOH})$, stannous sulfate $\left(\mathrm{SnSO}_{4}\right), \mathrm{PVDF}-\mathrm{HFP}$, and fumed nano- $\mathrm{SiO}_{2}$ were purchased from Aladdin (Shanghai, China).

\section{Fabrication of the $\mathrm{Cu} @ S n$ nanocones}

\section{Synthesis of the $\mathrm{Cu}$ nanocones}

$\mathrm{Cu}$ foil was soaked in $0.5 \mathrm{~mol} \mathrm{~L}^{-1} \mathrm{H}_{2} \mathrm{SO}_{4}$, acetone, and absolute ethanol for $30 \mathrm{~min}$, washed with ultrapure water, and dried in a vacuum oven at $60^{\circ} \mathrm{C}$ for $12 \mathrm{~h}$. A $100-\mathrm{mL}$ aqueous solution was prepared using $0.03 \mathrm{~mol} \mathrm{~L}^{-1}$ $\mathrm{CuSO}_{4} \cdot 5 \mathrm{H}_{2} \mathrm{O}, 0.0024 \mathrm{~mol} \mathrm{~L}^{-1} \mathrm{NiSO}_{4} \cdot 6 \mathrm{H}_{2} \mathrm{O}, 0.24 \mathrm{~mol} \mathrm{~L}^{-1}$ $\mathrm{NaH}_{2} \mathrm{PO}_{2}, 0.05 \mathrm{~mol} \mathrm{~L}^{-1} \mathrm{Na}_{3} \mathrm{C}_{6} \mathrm{H}_{5} \mathrm{O}_{7}, 0.5 \mathrm{~mol} \mathrm{~L}^{-1} \mathrm{H}_{3} \mathrm{BO}_{3}$, and $6 \mathrm{~g} \mathrm{~L}^{-1} \mathrm{PEG}$, and its $\mathrm{pH}$ was adjusted to 8.0 using $\mathrm{NaOH}$. Electrodeposition was performed at a potential of $-1.12 \mathrm{~V}$ at $75^{\circ} \mathrm{C}$ for $30 \mathrm{~min}$ using the treated $\mathrm{Cu}$ foil, $\mathrm{Pt}$ sheet, and saturated $\mathrm{Ag} / \mathrm{AgCl}$ as the working, counter, and reference electrodes, respectively. The deposited $\mathrm{Cu}$ foil was soaked in $0.1 \mathrm{~mol} \mathrm{~L}^{-1} \mathrm{H}_{2} \mathrm{SO}_{4}$ for $1 \mathrm{~h}$, rinsed with ultrapure water, and dried in a vacuum oven at $60^{\circ} \mathrm{C}$.

\section{Fabrication of the Cu@Sn nanocones}

A $100-\mathrm{mL}$ aqueous solution was prepared using $2 \mathrm{~mol} \mathrm{~L}^{-1}$ $\mathrm{NaOH}, 0.1 \mathrm{~mol} \mathrm{~L}^{-1} \mathrm{Na}_{3} \mathrm{C}_{6} \mathrm{H}_{5} \mathrm{O}_{7}$, and $0.05 \mathrm{~mol} \mathrm{~L}^{-1} \mathrm{SnSO}_{4}$. Electrodeposition was performed at a current density of $3.3 \mathrm{~mA} \mathrm{~cm}^{-2}$ for varying time periods using the $\mathrm{Cu}$ nanocones, $\mathrm{Pt}$ sheet, and saturated $\mathrm{Ag} / \mathrm{AgCl}$ as the working, counter, and reference electrodes, respectively. The obtained $\mathrm{Cu@Sn} \mathrm{nanocones} \mathrm{were} \mathrm{washed} \mathrm{with} \mathrm{ultrapure}$ water and dried in a vacuum oven at $60^{\circ} \mathrm{C}$.

\section{Preparation of the PVDF-HFP-based polymer electrolyte} PVDF-HFP $(2.0 \mathrm{~g})$ and nano- $\mathrm{SiO}_{2}$ particles were dispersed in $15 \mathrm{~mL}$ acetone and stirred at $50^{\circ} \mathrm{C}$ for $2 \mathrm{~h}$ to obtain homogenous viscous liquids. To obtain a polymer electrolyte membrane, the viscous liquids were scraped onto an $\mathrm{Al}$ foil and dried in a vacuum oven at $100^{\circ} \mathrm{C}$ for $12 \mathrm{~h}$. The membrane was cut into small pieces with 16 $\mathrm{mm}$ diameter and soaked in $1 \mathrm{~mol} \mathrm{~L}^{-1} \mathrm{Li}$ bis(trifluoromethanesulfonyl) imide (LiTFSI) in 1,3-dioxolane (DOL) and 1,2-dimethoxyethane (DME) (volume ratio = 1:1) with $1 \% \mathrm{LiNO}_{3}$ for $24 \mathrm{~h}$.

\section{Electrochemical measurements}

CR2032 coin batteries were assembled using the $\mathrm{Cu}$ foil or 3D Cu@Sn nanocones and Li metal foil as the working and counter electrodes, respectively, Celgard $2400 \mathrm{mi}-$ croporous polypropylene film as the separator, and $60 \mu \mathrm{L}$ of $1 \mathrm{~mol} \mathrm{~L}^{-1}$ LiTFSI in DOL/DME (volume ratio = 1:1) with $1 \% \mathrm{LiNO}_{3}$ as the electrolyte. All batteries were assembled in an argon (Ar)-filled glove box and tested on a multichannel battery tester (Land 2001A Battery Testing System) at $25^{\circ} \mathrm{C}$. For the CE test, a fixed amount of $\mathrm{Li}$ $\left(1 \mathrm{~mA} \mathrm{~h} \mathrm{~cm}{ }^{-2}\right)$ was deposited on the current collector and then stripped away up to $1 \mathrm{~V}$ at 0.5 or $1 \mathrm{~mA} \mathrm{~cm}^{-2}$ for each cycle. Further, the batteries were cycled at $1 \mathrm{~mA} \mathrm{~cm}^{-2}$ for varying time periods to characterize the morphology of the deposited $\mathrm{Li}$ on the $\mathrm{Cu}$ foil or $\mathrm{Cu} @ \mathrm{Sn}$ nanocones. For the symmetrical battery test, $\mathrm{Li}\left(3 \mathrm{~mA} \mathrm{~h} \mathrm{~cm}^{-2}\right)$ was first deposited on the $\mathrm{Cu}$ foil or 3D Cu@Sn nanocones at $1 \mathrm{~mA} \mathrm{~cm}^{-2}$. Then, the symmetrical batteries were charged/discharged at $1 \mathrm{~mA} \mathrm{~cm}{ }^{-2}$ for $1 \mathrm{~h}$ in each halfcycle. Then, the liquid full battery was assembled using LFP as the cathode, Cu foil or 3D Cu@Sn nanocones with predeposited $\mathrm{Li}\left(3 \mathrm{~mA} \mathrm{~h} \mathrm{~cm}{ }^{-2}\right)$ at $1 \mathrm{~mA} \mathrm{~cm}^{-2}$ as anodes, Celgard 2400 as the separator, and $1 \mathrm{~mol} \mathrm{~L}^{-1}$ LiTFSI in 
DOL/DME (volume ratio $=1: 1$ ) with $1 \% \mathrm{LiNO}_{3}$ as the electrolyte. Thereafter, the solid-state full battery was assembled using LFP as the cathode, 3D Cu@Sn nanocones with predeposited $\mathrm{Li}\left(3 \mathrm{~mA} \mathrm{~h} \mathrm{~cm}{ }^{-2}\right)$ at $1 \mathrm{~mA} \mathrm{~cm}^{-2}$ as the anode, and PVDF-HFP-based polymer as the electrolyte. The LFP electrolyte was prepared using a conventional doctor blade casting method. LFP, PVDF, and super $\mathrm{P}$ (mass ratio $=8: 1: 1$ ) were mixed and dispersed in $\mathrm{N}$-methyl-2-pyrrolidone (NMP) to achieve a homogeneous slurry. Then, the slurry was scraped onto the aluminum foil and dried in a vacuum drying oven at $80^{\circ} \mathrm{C}$ for $12 \mathrm{~h}$. The average mass loading of LFP in the electrode was approximately $2.5 \mathrm{mg} \mathrm{cm}^{-2}$. The full batteries were galvanostatically cycled between 2.4 and $4.0 \mathrm{~V}$ at $1 \mathrm{C}$.

\section{Characterization}

The morphology of the 3D Cu@Sn nanocones and $\mathrm{Li}$ deposition was observed using field-emission scanning electron microscopy (SEM, JEOL JSM-7500F) and scanning transmission electron microscopy (TEM) with elemental mapping recorded on FEI TALOX F200X G2. The contact angle was tested using a contact angle tester (TBU 100). The crystalline structures of the $\mathrm{Cu}$ foil, $\mathrm{Cu}$ nanocones, and $\mathrm{Cu} @ \mathrm{Sn}$ nanocones were characterized using powder X-ray diffraction (XRD, Rigaku MiniFlex600, Cu Ka radiation).

\section{RESULTS AND DISCUSSION}

A schematic illustration of the synthesis of the Cu@Sn nanocones is shown in Fig. 1a [34]. The $\mathrm{Cu}$ nanocones were prepared via electrodeposition at $-1.12 \mathrm{~V}$ versus saturated $\mathrm{Ag} / \mathrm{AgCl}$ for $30 \mathrm{~min}$ and soaked in $0.1 \mathrm{~mol} \mathrm{~L}^{-1}$ $\mathrm{H}_{2} \mathrm{SO}_{4}$ for $1 \mathrm{~h}$. Compared with the planar $\mathrm{Cu}$ foil (Fig. S1a, b), the surface of the $\mathrm{Cu}$ nanocones became tarnished after modifying the nanocones on the $\mathrm{Cu}$ foil (Fig. S1c). The SEM image (Fig. S1d) shows a rough surface covered with a dense and uniform nanocone array. The Cu@Sn nanocones were prepared via electrodeposition at $3.3 \mathrm{~mA} \mathrm{~cm}^{-2}$ to modify $\mathrm{Sn}$ on the $\mathrm{Cu}$ nanocones. The Cu@Sn nanocones with varying $\mathrm{Sn}$ contents were prepared by tuning the deposition time. As shown in Fig. S2a-f, the Cu@Sn nanocones maintain conical structure and no bulk Sn was observed on the surface when the deposition time was $20 \mathrm{~s}$. However, a small amount of bulk $\mathrm{Sn}$ appeared on the surface of the nanocones when the deposition time was $40 \mathrm{~s}$, and more bulk $S n$ appeared with an increase in the deposition time, which hindered the uniform nucleation of Li. Thus, the deposition time of Sn was set to $20 \mathrm{~s}$.
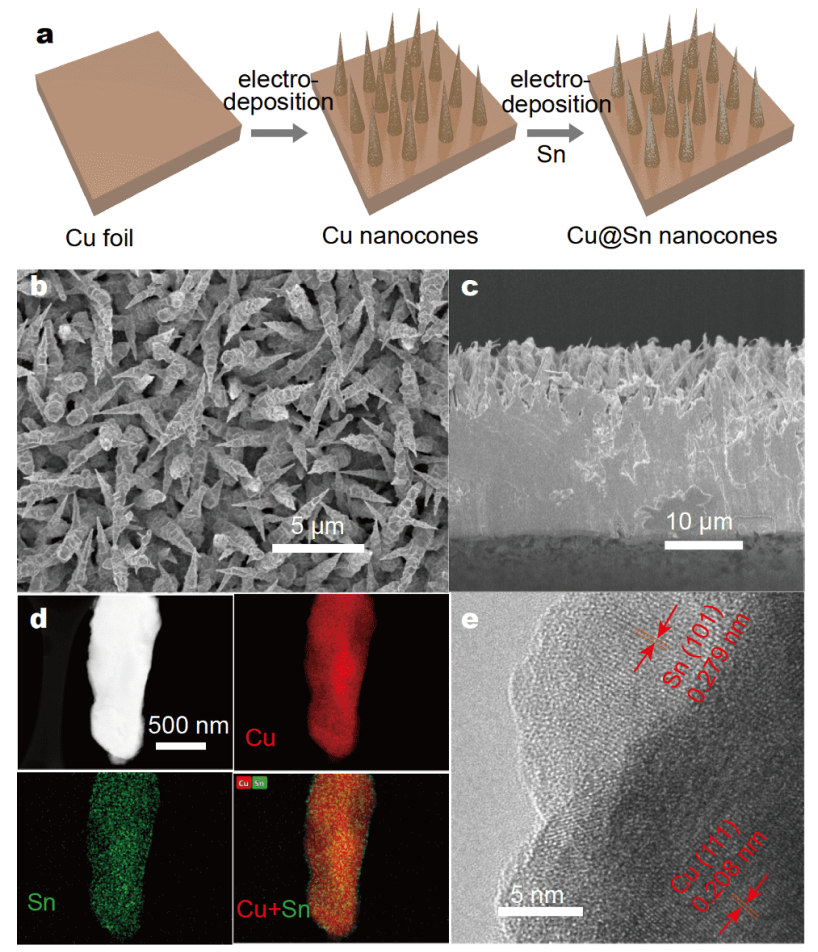

Figure 1 (a) Schematic illustration of the synthesis of the Cu@Sn nanocones. Top view (b) and cross-sectional (c) SEM images of the Cu@Sn nanocones. TEM elemental mapping (d) and high-resolution TEM image (e) of the Cu@Sn nanocones.

Fig. S3 shows the XRD patterns of the $\mathrm{Cu}$ foil, $\mathrm{Cu}$ nanocones, and Cu@Sn nanocones. The Cu foil and nanocone patterns show main peaks for $\mathrm{Cu}$ (JCPDs No. 040836), and a similar XRD pattern can be observed for the Cu@Sn nanocones. The characteristic peaks of Sn cannot be observed in the XRD pattern of $\mathrm{Cu@Sn} \mathrm{nanocones,}$ which can be attributed to its low quantity below the instrument detection limit. Fig. 1b-e show the characterization of the $\mathrm{Cu} @ \mathrm{Sn}$ nanocones with deposition time of $20 \mathrm{~s}$.

Fig. $1 \mathrm{~b}$ shows that the nanocone array is distributed on the surface of $\mathrm{Cu}$ foil. The thickness of the Cu@Sn nanocone current collector was approximately $20 \mu \mathrm{m}$, and the nanocone array maintained good contact with the $\mathrm{Cu}$ foil (Fig. 1c), ensuring rapid electron transmission. TEM and mapping (Fig. 1d) results show that the Sn nanoparticles were evenly distributed on the nanocone surface, ensuring uniform nucleation sites. Furthermore, the highresolution TEM image (Fig. 1e) shows an ordered crystal structure inside the nanocone with a lattice spacing of $0.208 \mathrm{~nm}$, ascribed to the $\mathrm{Cu}$ (111) plane; the outer lattice of the nanocone can be observed with a lattice spacing of $0.279 \mathrm{~nm}$, corresponding to the $\mathrm{Sn}$ (101) plane [30], 
which confirms the distribution of Sn nanoparticles on the $\mathrm{Cu}$ nanocone surface.

The contact angles of the planar $\mathrm{Cu}$ foil and Cu@Sn nanocones with the electrolyte $\left(1 \mathrm{~mol} \mathrm{~L}^{-1}\right.$ LiTFSI in DOL/ DME (volume ratio $=1: 1)+1 \% \mathrm{LiNO}_{3}$ ) were tested (Fig. S4). The electrolyte could not completely spread on the planar $\mathrm{Cu}$ foil with a contact angle of $31.57^{\circ}$. However, it could quickly expand on the Cu@Sn nanocone current collector, indicating improved wetting ability of the Cu@Sn nanocone current collector toward the electrolyte, which allows the rapid diffusion and uniform nucleation of Li ions. Moreover, the deposition behavior of $\mathrm{Li}$ on the $\mathrm{Cu}$ foil and $\mathrm{Cu} @ \mathrm{Sn}$ nanocones was investigated at a current density of $0.5 \mathrm{~mA} \mathrm{~cm}^{-2}$. Fig. 2 shows the morphology of Li deposited on the $\mathrm{Cu}$ foil and $\mathrm{Cu} @ \mathrm{Sn}$ nanocones under different deposition amounts $\left(0.5,1.0\right.$, and $\left.2.0 \mathrm{~mA} \mathrm{~h} \mathrm{~cm}^{-2}\right)$. Fig. 2a-c show the formation of dendritic $\mathrm{Li}$ on the $\mathrm{Cu}$ foil surface, and the dendritic morphology becomes more evident with an increase in the deposition amount. Dendritic Li may pierce the separator and cause a short circuit of the battery. Uniform granular Li was generated on the Cu@Sn nanocones rather than dendritic $\mathrm{Li}$, and a relatively flat surface was formed with an increase in the deposition amount. This observation was mainly attributed to the initially formed small Li dendrite tip, which acts as the charge center in the electric field, continuously accumulating charges, and Li deposited on these sharp tips amplified the Li dendrite growth. Conversely, the 3D structure of the $\mathrm{Cu@Sn} \mathrm{nanocones} \mathrm{dispersed} \mathrm{the} \mathrm{electric}$ field distribution, improving the uniformity of the charge distribution and promoting the uniform deposition of Li. Further, the uniform distribution of $\mathrm{Sn}$ on the nanocones can form uniform initial Li nucleation sites and regulate Li deposition. Consequently, a relatively uniform and flat Li deposition plane was formed under the synergy of the

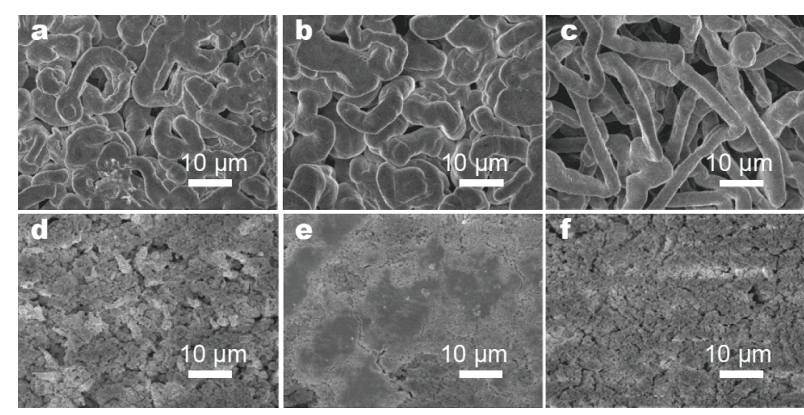

Figure 2 Morphology of Li deposited on the Cu foil and Cu@Sn nanocones at current densities of (a,d) $0.5 \mathrm{~mA} \mathrm{~h} \mathrm{~cm}^{-2}$, (b, e) $1 \mathrm{~mA} \mathrm{~h} \mathrm{~cm}^{-2}$, and (c, f) $2 \mathrm{~mA} \mathrm{~h} \mathrm{~cm}^{-2}$ on the $\mathrm{Cu}$ foil (a-c) and Cu@Sn nanocones (d-f). nanocone structure and Sn.

The interface energy between $\mathrm{Li}$ and the current collector determines the nucleation overpotential of $\mathrm{Li}$ on the current collector. Fig. 3 shows the voltage curve of Li deposited on the $\mathrm{Cu}$ foil, $\mathrm{Cu}$ nanocones, and $\mathrm{Cu} @ \mathrm{Sn}$ nanocones at a current density of $1 \mathrm{~mA} \mathrm{~cm}^{-2}$. The figure shows a large nucleation overpotential of $240 \mathrm{mV}\left(v s . \mathrm{Li}^{+} /\right.$ $\mathrm{Li}$ ) when $\mathrm{Li}$ was deposited on the planar $\mathrm{Cu}$ foil and a reduced nucleation overpotential of $211 \mathrm{mV}\left(v s . \mathrm{Li}^{+} / \mathrm{Li}\right)$ on the $\mathrm{Cu}$ nanocones. However, after modification using $\mathrm{Sn}$, the nucleation overpotential of Li deposited on the $\mathrm{Cu} @ \mathrm{Sn}$ nanocones significantly reduced and was considerably lower than that of the $\mathrm{Cu}$ foil and $\mathrm{Cu}$ nanocones. The $3 \mathrm{D}$ structure possesses a large surface area, which can reduce the local current density, thereby decreasing the Li nucleation overpotential. Besides, $\mathrm{Li}$ ions first react with $\mathrm{Sn}$ to form $\mathrm{Li}-\mathrm{Sn}$ alloys owing to the modification with Sn [35-37], which provides numerous active sites to promote $\mathrm{Li}$ nucleation $[38,39]$. Thus, the deposition of Li on Cu@Sn nanocones exhibited a lower nucleation overpotential than on $\mathrm{Cu}$ foil and $\mathrm{Cu}$ nanocones.

To investigate the plating/stripping behavior of $\mathrm{Li}$ on the $\mathrm{Cu}$ foil and $\mathrm{Cu} @ S n$ nanocones, $\mathrm{Li} / \mathrm{Cu}$ and Li/Cu@Sn half batteries were assembled using $1 \mathrm{~mol} \mathrm{~L}^{-1}$ LiTFSI in DOL/DME (volume ratio $=1: 1$ ) and $1 \% \mathrm{LiNO}_{3}$. Fig. $4 \mathrm{a}$ shows the CEs of the $\mathrm{Cu}$ foil and Cu@Sn nanocone electrodes cycled at a current density of $0.5 \mathrm{~mA} \mathrm{~cm}^{-2}$ with an areal capacity of $0.5 \mathrm{~mA} \mathrm{~h} \mathrm{~cm}{ }^{-2}$. The $\mathrm{CE}$ of the planar $\mathrm{Cu}$ foil started to decrease and became unstable after 180 cycles; the CE was only $56.8 \%$ after 250 cycles. The CE of the Cu@Sn nanocones was stable at $96.9 \%$ after $250 \mathrm{cy}-$ cles, which was considerably higher than that of the $\mathrm{Cu}$ foil. At a current density of $1 \mathrm{~mA} \mathrm{~cm}^{-2}$ with an areal

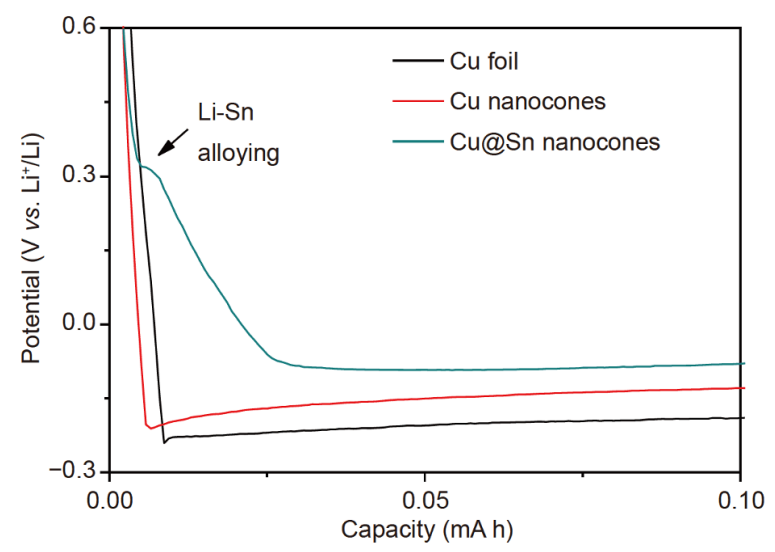

Figure 3 Voltage curves of $\mathrm{Li}$ deposited on the $\mathrm{Cu}$ foil, $\mathrm{Cu}$ nanocones, and Cu@Sn nanocones at a current density of $1 \mathrm{~mA} \mathrm{~cm}^{-2}$. 

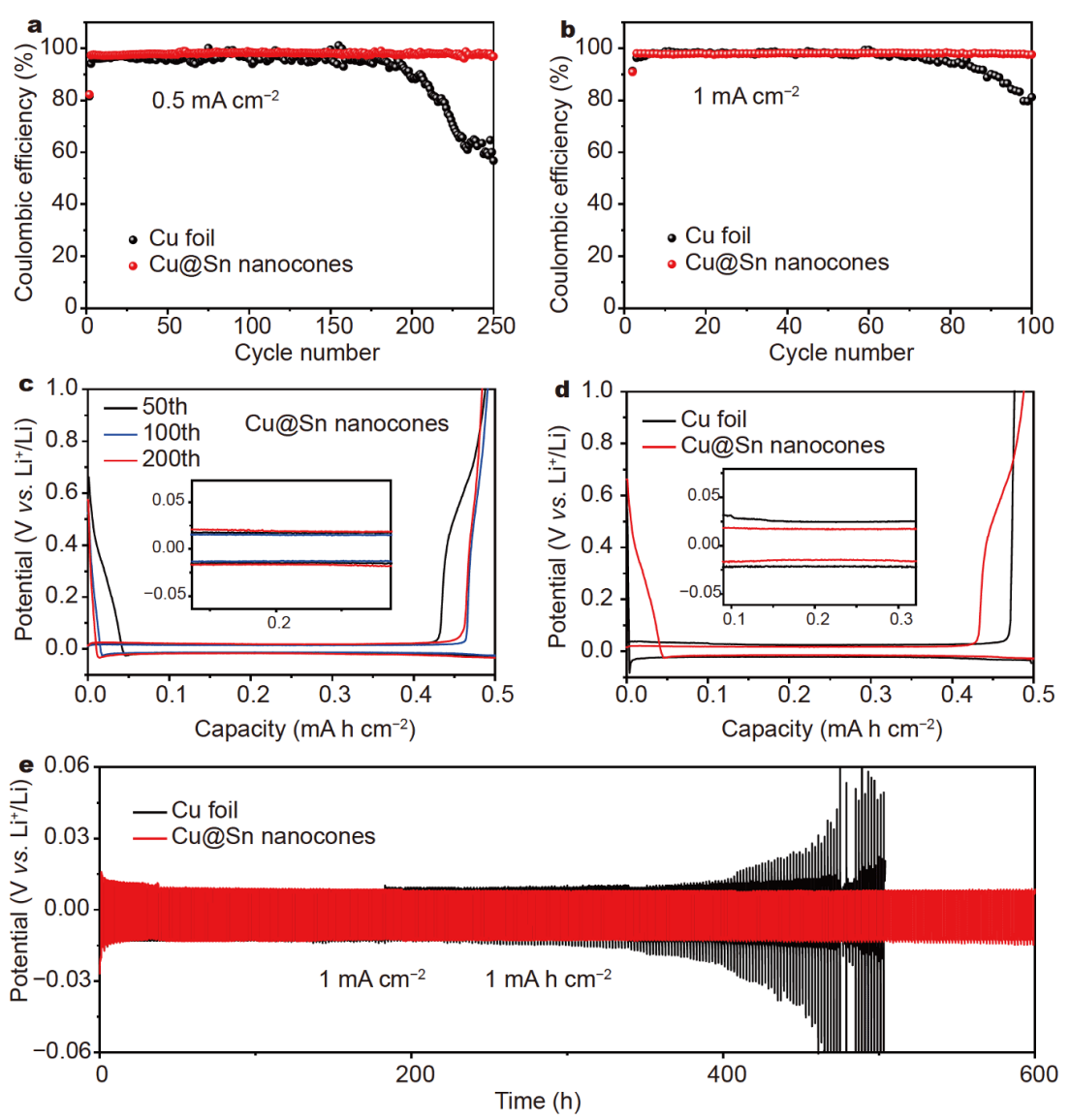

Figure 4 CEs of Li deposited on the Cu foil and Cu@Sn nanocone electrodes at current densities of (a) 0.5 and (b) $1 \mathrm{~mA} \mathrm{~cm}^{-2}$. (c) Voltage profiles of Li plating/stripping on the Cu@Sn nanocones during the 50th, 100th, and 200th cycles at a current density of $0.5 \mathrm{~mA} \mathrm{~cm}{ }^{-2}$. (d) Voltage profiles of Li plating/stripping on the Cu@Sn nanocones and $\mathrm{Cu}$ foil at the current density of $0.5 \mathrm{~mA} \mathrm{~cm}^{-2}$. (e) Li symmetrical battery (predeposited Li at $3 \mathrm{~mA} \mathrm{~h} \mathrm{~cm}^{-2}$ ) based on the $\mathrm{Cu}$ foil and Cu@Sn nanocones at the current density of $1 \mathrm{~mA} \mathrm{~cm}^{-2}$ under the areal capacity of $1 \mathrm{~mA} \mathrm{~h} \mathrm{~cm}^{-2}$.

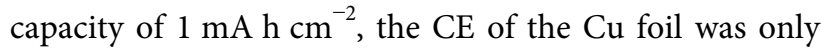
$81.2 \%$ after 100 cycles and that of the Cu@Sn nanocones remained at $97.6 \%$ (Fig. $4 \mathrm{~b}$ ), because the Li dendrites generated on the $\mathrm{Cu}$ foil may fall from the root and become dead $\mathrm{Li}$ after losing electrical contact during the stripping process, which reduces the CE of the battery. However, the Cu@Sn nanocones can effectively suppress $\mathrm{Li}$ dendrites, thus ensuring high $\mathrm{CE}$. Fig. $4 \mathrm{c}$ shows the voltage profiles of $\mathrm{Li}$ plating/stripping on the $\mathrm{Cu} @ \mathrm{Sn}$ nanocones during the 50th, 100th, and 200th cycles at the current density of $0.5 \mathrm{~mA} \mathrm{~cm}{ }^{-2}$ with an areal capacity of $0.5 \mathrm{~mA} \mathrm{~h} \mathrm{~cm}^{-2}$. The almost overlapped charge/discharge curves indicate the excellent cycling stability of the $\mathrm{Cu} @ \mathrm{Sn}$ nanocones and show smaller voltage hysteresis than those of the $\mathrm{Cu}$ foil (Fig. $4 \mathrm{~d}$ ). The smaller voltage hysteresis of the Cu@Sn nanocones can be attributed to the large specific surface area and good wettability with liquid electrolyte to ensure rapid Li-ion transmission. To further investigate the stability of the Cu@Sn nanocone current collector during cycling, symmetrical batteries were assembled. The polarization voltage of the Cu@Sn nanocone-based battery was approximately $10 \mathrm{mV}$ at the current density of $1 \mathrm{~mA} \mathrm{~cm}^{-2}$ and could stably cycle for more than $600 \mathrm{~h}$ (Fig. 4e). However, the $\mathrm{Cu}$ foil-based battery started to become unstable after $350 \mathrm{~h}$, and its polarization voltage began to sharply increase after $400 \mathrm{~h}$. These results indicate the excellent stability of the Cu@Sn nanocones during prolonged cycling.

To evaluate the application of the Cu@Sn nanocones in batteries, the $\mathrm{Cu}$ foil and $\mathrm{Cu@Sn} \mathrm{nanocones} \mathrm{with} \mathrm{pre-}$ deposited $\mathrm{Li}\left(3 \mathrm{~mA} \mathrm{~h} \mathrm{~cm}^{-2}\right)$ as the anodes and LFP as the cathode were used to assemble full batteries, correspondingly denoted as Li/Cu|LFP and Li/Cu@Sn|LFP. Fig. 5a, b demonstrate the galvanostatic charge/discharge voltage curves of $\mathrm{Li} / \mathrm{Cu} \mid \mathrm{LFP}$ and Li/Cu@Sn|LFP at $1 \mathrm{C}$ from 2.4 to $4.0 \mathrm{~V}$. The Li/Cu@Sn|LFP battery showed a smaller overpotential than the $\mathrm{Li} / \mathrm{Cu} \mid \mathrm{LFP}$ battery. The initial discharge capacity of the Li/Cu@Sn|LFP battery 

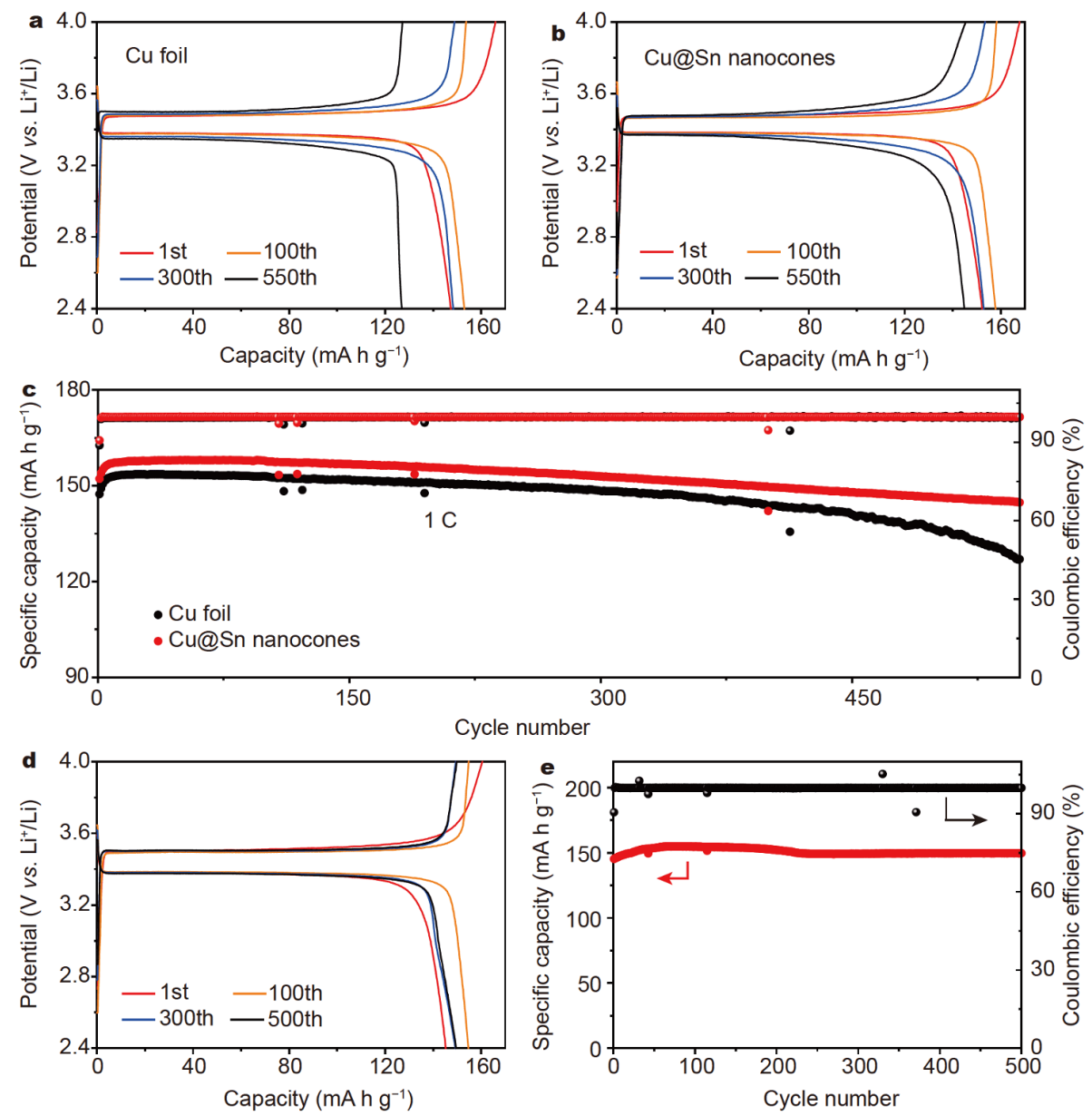

Figure 5 Galvanostatic charge/discharge voltage profiles of the Li/Cu|LFP (a) and Li/Cu@Sn|LFP (b) batteries at 1 C from 2.4 to 4.0 V. (c) Cyclic performances of the Li/Cu|LFP and Li/Cu@Sn|LFP batteries at $1 \mathrm{C}$. (d) Galvanostatic charge/discharge voltage profiles of the solid-state battery at room temperature at $1 \mathrm{C}$ from 2.4 to $4.0 \mathrm{~V}$. (e) Cyclic performance of the solid-state battery at $1 \mathrm{C}$.

was $152.2 \mathrm{~mA} \mathrm{~h} \mathrm{~g}^{-1}$ with $95.1 \%$ capacity retention after 550 cycles. However, the initial discharge capacity of the $\mathrm{Li} / \mathrm{Cu}$ LFP battery was $147.2 \mathrm{~mA} \mathrm{~h} \mathrm{~g}^{-1}$ with only $86.2 \%$ capacity retention after 550 cycles. Fig. $5 c$ shows the long cycle performance of the Li/Cu|LFP and Li/Cu@Sn|LFP batteries at $1 \mathrm{C}$. The Li/Cu@Sn|LFP battery showed better cycle stability than the Li/Cu|LFP battery, and the discharge capacity did not significantly decay after $550 \mathrm{cy}$ cles.

The Cu@Sn nanocones could suppress Li dendrites and improve the safety performance of liquid batteries. However, the safety hazards associated with the use of liquid electrolytes are still inevitable. Thus, a PVDFHFP-5 wt $\% \mathrm{SiO}_{2}$ solid-state electrolyte was prepared, and the application of the $\mathrm{Cu} @ \mathrm{Sn}$ nanocones current collector in solid-state batteries was investigated. The use of a solid-state electrolyte and Cu@Sn nanocones is expected to further improve the safety performance of batteries. The impedance of PVDF-HFP-5 wt $\% \mathrm{SiO}_{2}$ soaked in $1 \mathrm{~mol} \mathrm{~L}^{-1}$ LiTFSI in DOL/DME (volume ratio $=1: 1$ ) with $1 \% \mathrm{LiNO}_{3}$ at room temperature was evaluated (Fig. S5), and the ion conductivity at room temperature was found to be $2.07 \times 10^{-4} \mathrm{~S} \mathrm{~cm}^{-1}$. The $\mathrm{Cu@Sn} \mathrm{nanocones} \mathrm{with}$ predeposited $\mathrm{Li}\left(3 \mathrm{~mA} \mathrm{~h} \mathrm{~cm}{ }^{-2}\right)$ as the anode and LFP as the cathode with the PVDF-HFP-5 wt\% $\mathrm{SiO}_{2}$-based electrolyte were used to assemble the full solid-state batteries (Li/Cu@Sn|PVDF-HFP-5 wt\% $\mathrm{SiO}_{2} \mid \mathrm{LFP}$ ), and the electrochemical performance of the $\mathrm{Cu} @ \mathrm{Sn}$ nanocones in solid-state batteries was tested at room temperature. Fig. 5d demonstrates the galvanostatic charge/ discharge voltage profiles of $\mathrm{Li} / \mathrm{Cu} @ S n \mid$ PVDF-HFP$5 \mathrm{wt} \% \mathrm{SiO}_{2} \mid \mathrm{LFP}$ at $1 \mathrm{C}$ from 2.4 to $4.0 \mathrm{~V}$, in which the initial discharge capacity was $145.2 \mathrm{~mA} \mathrm{~h} \mathrm{~g}^{-1}$ and the discharge capacity did not undergo decay after 500 cycles. Fig. 5e shows the long cycle performance of the Li/ $\mathrm{Cu} @ \mathrm{Sn} \mid$ PVDF-HFP-5 wt\% $\mathrm{SiO}_{2}$ LFP batteries at $1 \mathrm{C}$. 
The solid-state batteries exhibited excellent cyclic stability (Fig. 5e), which was comparable to that of liquid batteries.

\section{CONCLUSIONS}

The 3DCu@Sn nanocones with small volume, light weight, and lithiophilic characteristics were prepared on the planar $\mathrm{Cu}$ foil by an electrodeposition method. The nanocone structure can disperse the current density, which improves the uniformity of the electric field distribution and promotes the uniform deposition of Li. Moreover, Sn can react with $\mathrm{Li}$ to form a $\mathrm{Li}-\mathrm{Sn}$ alloy, forming numerous $\mathrm{Li}$ active sites and regulating $\mathrm{Li}$ deposition. The synergy of the nanocone structure and Sn effectively inhibits the formation of Li dendrites. The Li/ Cu@Sn battery exhibits a high CE of 97.6\% after 100 cycles at the current density of $1 \mathrm{~mA} \mathrm{~cm}{ }^{-2}$. The symmetrical battery can stably cycle for more than $600 \mathrm{~h}$ at the current density of $1 \mathrm{~mA} \mathrm{~cm}^{-2}$. The liquid full battery Li/ $\mathrm{Cu@Sn|LFP} \mathrm{exhibits} \mathrm{excellent} \mathrm{cyclic} \mathrm{stability,} \mathrm{and} \mathrm{the}$ capacity retention was maintained at $95.1 \%$ after 550 cycles. Moreover, the Cu@Sn nanocone current collector exhibits excellent electrochemical performance in the solid-state Li/Cu@Sn|PVDF-HFP-5 wt\% $\mathrm{SiO}_{2} \mid$ LFP battery, and the capacity does not decay after 500 cycles at 1 C. Conclusively, this study provides a strategy for preparing 3D current collectors for high-energy-density LMBs, which may be used to fabricate other metal current collectors or metal batteries.

Received 9 June 2020; accepted 22 September 2020;

published online 16 December 2020

1 Xu W, Wang J, Ding F, et al. Lithium metal anodes for rechargeable batteries. Energy Environ Sci, 2014, 7: 513-537

2 Hwang SM, Kim SY, Kim JG, et al. Electrospun manganese-cobalt oxide hollow nanofibres synthesized via combustion reactions and their lithium storage performance. Nanoscale, 2015, 7: 8351-8355

3 Lee J, Moon J, Han SA, et al. Everlasting living and breathing gyroid 3D network in $\mathrm{Si}_{\mathrm{SiO}} / \mathrm{C}$ nanoarchitecture for lithium ion battery. ACS Nano, 2019, 13: 9607-9619

4 Xiao Z, Li Z, Meng X, et al. MXene-engineered lithium-sulfur batteries. J Mater Chem A, 2019, 7: 22730-22743

$5 \mathrm{Yu} \mathrm{W}$, Xue C, Hu B, et al. Oxygen- and dendrite-resistant ultra-dry polymer electrolytes for solid-state $\mathrm{Li}-\mathrm{O}_{2}$ batteries. Energy Storage Mater, 2020, 27: 244-251

$6 \mathrm{Hu} \mathrm{X}, \mathrm{Li} \mathrm{Z}$, Chen J. Flexible $\mathrm{Li}-\mathrm{CO}_{2}$ batteries with liquid-free electrolyte. Angew Chem Int Ed, 2017, 56: 5785-5789

7 Wang R, Zhang X, Cai Y, et al. Safety-reinforced rechargeable Li$\mathrm{CO}_{2}$ battery based on a composite solid state electrolyte. Nano Res, 2019, 12: 2543-2548

8 Jung KN, Kim J, Yamauchi Y, et al. Rechargeable lithium-air batteries: a perspective on the development of oxygen electrodes. J Mater Chem A, 2016, 4: 14050-14068

9 Cheng XB, Zhang R, Zhao CZ, et al. Toward safe lithium metal anode in rechargeable batteries: A review. Chem Rev, 2017, 117: 10403-10473

10 Lin D, Liu Y, Cui Y. Reviving the lithium metal anode for highenergy batteries. Nat Nanotech, 2017, 12: 194-206

11 Albertus P, Babinec S, Litzelman S, et al. Status and challenges in enabling the lithium metal electrode for high-energy and low-cost rechargeable batteries. Nat Energy, 2017, 3: 16-21

12 Liu $\mathrm{H}$, Cheng $\mathrm{XB}$, Jin $\mathrm{Z}$, et al. Recent advances in understanding dendrite growth on alkali metal anodes. EnergyChem, 2019, 1: 100003

13 Ding F, Xu W, Graff GL, et al. Dendrite-free lithium deposition via self-healing electrostatic shield mechanism. J Am Chem Soc, 2013, 135: 4450-4456

14 Ma Q, Sun X, Liu P, et al. Bio-inspired stable lithium-metal anodes by Co-depositing lithium with a $2 \mathrm{D}$ vermiculite shuttle. Angew Chem Int Ed, 2019, 58: 6200-6206

15 Yang Y, Xiong J, Lai S, et al. Vinyl ethylene carbonate as an effective SEI-forming additive in carbonate-based electrolyte for lithium-metal anodes. ACS Appl Mater Interfaces, 2019, 11: 61186125

16 Xu R, Zhang XQ, Cheng XB, et al. Lithium metal anodes: Artificial soft-rigid protective layer for dendrite-free lithium metal anode. Adv Funct Mater, 2018, 28: 1705838

17 Li NW, Yin YX, Yang CP, et al. An artificial solid electrolyte interphase layer for stable lithium metal anodes. Adv Mater, 2016, 28: $1853-1858$

18 Kang D, Sardar S, Zhang R, et al. In-situ organic SEI layer for dendrite-free lithium metal anode. Energy Storage Mater, 2020, 27: 69-77

19 Pan K, Zhang L, Qian W, et al. A flexible ceramic/polymer hybrid solid electrolyte for solid-state lithium metal batteries. Adv Mater, 2020, 32: 2000399

20 Zhao CZ, Zhang XQ, Cheng XB, et al. An anion-immobilized composite electrolyte for dendrite-free lithium metal anodes. Proc Natl Acad Sci USA, 2017, 114: 11069-11074

21 Zeng XX, Yin YX, Li NW, et al. Reshaping lithium plating/stripping behavior via bifunctional polymer electrolyte for room-temperature solid Li metal batteries. J Am Chem Soc, 2016, 138: $15825-15828$

22 Wang SH, Yin YX, Zuo TT, et al. Stable Li metal anodes via regulating lithium plating/stripping in vertically aligned microchannels. Adv Mater, 2017, 29: 1703729

23 Yang CP, Yin YX, Zhang SF, et al. Accommodating lithium into 3D current collectors with a submicron skeleton towards long-life lithium metal anodes. Nat Commun, 2015, 6: 8058

24 Zuo TT, Wu XW, Yang CP, et al. Graphitized carbon fibers as multifunctional 3D current collectors for high areal capacity $\mathrm{Li}$ anodes. Adv Mater, 2017, 29: 1700389

25 Qiu $\mathrm{H}$, Tang $\mathrm{T}$, Asif $\mathrm{M}$, et al. 3D porous $\mathrm{Cu}$ current collectors derived by hydrogen bubble dynamic template for enhanced $\mathrm{Li}$ metal anode performance. Adv Funct Mater, 2019, 29: 1808468

26 Li Q, Zhu S, Lu Y. 3D porous $\mathrm{Cu}$ current collector/Li-metal composite anode for stable lithium-metal batteries. Adv Funct Mater, 2017, 27: 1606422

27 Yang Y, Xiong J, Zeng J, et al. VGCF 3D conducting host coating on glass fiber filters for lithium metal anodes. Chem Commun, 2018, 54: 1178-1181

28 Zhang C, Lv W, Zhou G, et al. Vertically aligned lithiophilic $\mathrm{CuO}$ nanosheets on a $\mathrm{Cu}$ collector to stabilize lithium deposition for lithium metal batteries. Adv Energy Mater, 2018, 8: 1703404 
Lu LL, Zhang Y, Pan Z, et al. Lithiophilic Cu-Ni core-shell nanowire network as a stable host for improving lithium anode performance. Energy Storage Mater, 2017, 9: 31-38

30 Zhang D, Dai A, Wu M, et al. Lithiophilic 3D porous CuZn current collector for stable lithium metal batteries. ACS Energy Lett, 2020, 5: 180-186

31 Yue XY, Wang WW, Wang QC, et al. CoO nanofiber decorated nickel foams as lithium dendrite suppressing host skeletons for high energy lithium metal batteries. Energy Storage Mater, 2018, 14: 335-344

32 Chen L, Connell JG, Nie A, et al. Lithium metal protected by atomic layer deposition metal oxide for high performance anodes. J Mater Chem A, 2017, 5: 12297-12309

33 Chen KH, Sanchez AJ, Kazyak E, et al. Synergistic effect of 3D current collectors and ALD surface modification for high coulombic efficiency lithium metal anodes. Adv Energy Mater, 2019, 9: 1802534

34 Chen C, Pang Y, Zhang F, et al. Sharp Cu@Sn nanocones on Cu foam for highly selective and efficient electrochemical reduction of $\mathrm{CO}_{2}$ to formate. J Mater Chem A, 2018, 6: 19621-19630

35 Hwang SM, Lim YG, Kim JG, et al. A case study on fibrous porous $\mathrm{SnO}_{2}$ anode for robust, high-capacity lithium-ion batteries. Nano Energy, 2014, 10: 53-62

36 Xue $\mathrm{H}$, Zhao J, Tang J, et al. High-loading nano- $\mathrm{SnO}_{2}$ encapsulated in situ in three-dimensional rigid porous carbon for superior lithium-ion batteries. Chem Eur J, 2016, 22: 4915-4923

37 Luo Z, Xu JC, Yuan B, et al. A novel 3D bimodal porous current collector with large interconnected spherical channels for improved capacity and cycling stability of Sn anode in Li-ion batteries. Mater Lett, 2018, 213: 189-192

38 Zhang $\mathrm{Y}$, Wang $\mathrm{C}$, Pastel G, et al. 3D wettable framework for dendrite-free alkali metal anodes. Adv Energy Mater, 2018, 8: 1800635

39 Luo Z, Liu C, Tian Y, et al. Dendrite-free lithium metal anode with lithiophilic interphase from hierarchical frameworks by tuned nucleation. Energy Storage Mater, 2020, 27: 124-132

Acknowledgements This study was supported by the National Natural Science Foundation of China (51771094 and 21835004), the National Key R\&D Program of China (2016YFB0901500), the Ministry of Education of China (B12015 and IRT13R30), and Tianjin Natural Science Foundation (18JCZDJC31500).

Author contributions Wang R and Shi F conceived the project and prepared the current collector. He X, Shi J, and Ma T helped with the characterization. Wang $\mathrm{R}$ and Shi $\mathrm{F}$ wrote the paper with support from Tao Z. All authors contributed to the general discussion.

Conflict of interest The authors declare that they have no conflict of interest.

Supplementary information Experimental details and supporting data are available in the online version of the paper.

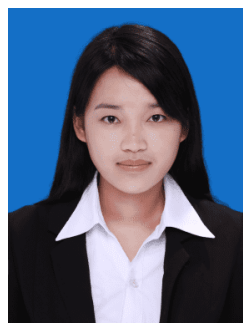

Rui Wang received her bachelor's degree in applied chemistry from Central South University in 2017. Currently, she is a graduate student under the supervision of Prof. Zhanliang Tao at the College of Chemistry, Nankai University. Her research interest focuses on lithium metal anodes and solid-state electrolytes.

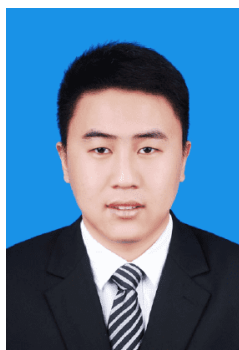

Faxing Shi received his bachelor's degree from Central South University in 2017. He is a graduate student at the College of Chemistry, Nankai University. His research interests are the syntheses of novel metal nanomaterials and characterization of interface for nanostructures.

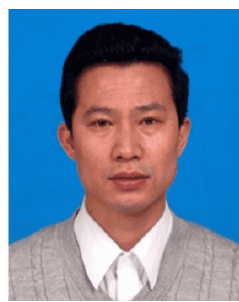

Zhanliang Tao received his $\mathrm{PhD}$ in inorganic chemistry from Nankai University in 2005 and is now a professor at the College of Chemistry, Nankai University. His research interest focuses on electrochemical energy storage and conversion.

\section{三维亲锂 $\mathrm{Cu} @ S n$ 纳米雉集流体用于无枝晶锂金属 负极}

王荵 ${ }^{\dagger}$, 石发兴 ${ }^{\dagger}$, 贺釒, 史金强, 马陶, 金松, 陶占良

摘要 锂在集流体上的不均匀沉积将导致严重的枝晶生长和体积 膨胀等问题，传统的商业化泡沫铜集流体由于具有较大的体积和 质量会降低电池的能量密度. 本文通过简单的电沉积方法制备了 体积小、重量轻, 具有亲锂性的 $3 \mathrm{D} \mathrm{Cu} @ \mathrm{Sn}$ 纳米雉集流体. 从成核 与沉积的角度出发, 纳米锥结构与亲锂的锡纳米颗粒的协同作用 促进了锂的均匀沉积, 可有效地抑制锂枝晶的生长. 组装的半电池 在 $1 \mathrm{~mA} \mathrm{~cm}^{-2}$ 下经过 100 次循环后, 库仑效率高达 $97.6 \%$, 锂对称电 池在 $1 \mathrm{~mA} \mathrm{~cm}^{-2}$ 下可以稳定循环 $600 \mathrm{~h}$. 将沉积金属锂后的 $\mathrm{Cu} @ \mathrm{Sn} /$ $\mathrm{Li}$ 复合负极与 $\mathrm{LiFePO}_{4}$ 组装的液态全电池在 1 C倍率下, 550 个循环 之后, 容量保持率为 $95.1 \%$. 此外, Cu@Sn纳米雉集流体在固态电池 $\mathrm{Li} / \mathrm{Cu} @ \mathrm{Sn} \mid$ PVDF-HFP-5 wt\% $\mathrm{SiO}_{2}$ LFP中也表现出优异的电化学 性能, 在 $1 \mathrm{C}$ 倍率下, 500 个循环之后, 放电容量未发生衰减. 